\title{
Relationship of strontium isotope ratio and chemical composition of micro inclusions in fibrous diamonds: Implication for isotopically different components of the upper mantle
}

\begin{abstract}
TASUKU AKAGI
Faculty of Agriculture, Tokyo University of Agriculture and Technology, Saiwaicho, Fuchu, Tokyo 183, Japan

(Received November 7, 1997; Accepted October 29, 1998)

Strontium isotope ratios in whole fibrous diamonds from Zaire do not correlate with $\mathrm{Rb} / \mathrm{Sr}$ ratios, but with $\mathrm{La} / \mathrm{Ba}$ and $\mathrm{La} / \mathrm{Nd}$ ratios. Diamonds with lower $\mathrm{La} / \mathrm{Ba}$ and higher $\mathrm{La} / \mathrm{Nd}$ gave higher ${ }^{87} \mathrm{Sr} /{ }^{86} \mathrm{Sr}$. Leaching experiments on crushed diamonds gave lower $\mathrm{La} / \mathrm{Ba}$ and higher $\mathrm{La} / \mathrm{Nd}$ for water leachate and higher $\mathrm{La} / \mathrm{Ba}$ and lower $\mathrm{La} / \mathrm{Nd}$ for acid leachate, and more importantly, the former has higher ${ }^{87} \mathrm{Sr} /{ }^{86} \mathrm{Sr}$ ratios than the latter, which is in accord with the experiments of whole diamonds. The two leachates are considered to be from water-rich fluid and carbonates, respectively. It is likely that the diamonds have formed in the environment where water-rich fluid and carbonate-rich fluid or melt were mixing and that the mixing may have triggered kimberlitic magmatism.
\end{abstract}

\section{INTRODUCTION}

Fibrous diamonds contain numerous micro $(<1$ $\mu \mathrm{m})$ inclusions consisting of water, carbonates and incompatible elements (Melton and Giardini, 1974; Navon et al., 1988). The fibrous texture indicates rapid growth (Boyd et al., 1994), during which fluids from the upper mantle can be incorporated. An IR study disclosed that the inclusions still retain pressure corresponding to that of the upper mantle (Navon, 1991). The diamonds are valuable sources of information about the composition of fluids in the upper mantle (Akagi and Masuda, 1988; Navon et al., 1988; Boyd et al., 1987; Ozima et al., 1989; Schrauder and Navon, 1994; Schrauder et al., 1996). Schrauder and Navon (1994) reported that the composition of the fluids varies between carbonatitic and hydrous end members.

My previous study revealed that the strontium isotopic ratios of fibrous Zairean diamonds ranged from 0.704 to 0.705 (Akagi and Masuda, 1988). The ratios were in the range of host kimberlite, and they showed no relation with $\mathrm{Rb} / \mathrm{Sr}$ concentration ratios, failing to form a $\mathrm{Rb}-\mathrm{Sr}$ isochron
(Akagi and Masuda, 1988). The previous study has focussed only on the relation with host kimberlite, whereas the environment of the upper mantle had escaped my attention. For examining the isotopically heterogeneous environment in the upper mantle (Faure, 1986), fibrous diamonds could be ideal specimens, since it is expected that the chemical conditions are recorded intact in diamond crystals, free from the effects of weathering and metamorphism. The aim of the present study is to characterize the chemical feature on the environment of the upper mantle using the fibrous diamonds.

\section{METHOD}

I undertook some additional experiments on some fibrous diamonds from the same batch of my previous study (Akagi and Masuda, 1988) to extract trace elements from diamonds. One is a combustion method, where diamonds are combusted under the oxygen and elements of interest are recovered by acids. The second is a leaching method, in which the crushed diamonds were sonicated twice with water and then with hydro- 
chloric acid twice. In the leaching experiments, the two water and two acid leachates are combined in separate beakers before analysis. The concentration of elements in diamond lattices are assumed negligibly small compared with those in micro inclusions. It is expected that the combustion method liberates all the REE, $\mathrm{Sr}, \mathrm{Ba}$, and $\mathrm{Rb}$ from the micro inclusions trapped in fibrous coat of diamonds or in cracks, whereas the leaching method extracts only part of the elements on the surface of diamond chips made exposed by crushing. Elemental abundance was measured by isotope dilution.

\section{RESULTS}

\section{Combustion experiments}

The concentrations of $\mathrm{REE}, \mathrm{Rb}, \mathrm{Sr}$ and $\mathrm{Ba}$, and $\mathrm{Sr}$ isotopic data are summarized in Table 1 . Only one set of data (sample CS-12) in Table 1 is new data in the combustion experiments, and the remainder are from my previous paper (Akagi and Masuda, 1988). Scrutiny of the chondrite normalized $\mathrm{REE}, \mathrm{Rb}, \mathrm{Sr}$ and $\mathrm{Ba}$ patterns of the diamonds from the combustion experiment discloses covariation between the shapes of the pattern and $\mathrm{REE} / \mathrm{Ba}$ ratios (Fig. 1), i.e., in two patterns $\mathrm{Nd}$ is under the line connecting $\mathrm{La}$ and $\mathrm{Gd}$ and the line extends toward $\mathrm{Ba}$ (high $\mathrm{La} / \mathrm{Nd}$ and low $\mathrm{Nd} / \mathrm{Ba}$ ); in the other four patterns $\mathrm{Nd}$ is above the $\mathrm{La}-\mathrm{Gd}$ line which kinks abruptly to connect $\mathrm{Ba}$ (low $\mathrm{La}$ / $\mathrm{Nd}$ and high $\mathrm{Nd} / \mathrm{Ba}$ ). In order to exhibit the trend more clearly the relationship between $\mathrm{La} / \mathrm{Nd}$ and $\mathrm{Nd} / \mathrm{Ba}$ is shown in Fig. 2, where the data of Botswana diamonds by Schrauder et al. (1996) are also plotted. The present six data are plotted along the same line formed by the Botswana diamonds, although the data of Botswana diamonds are dis-

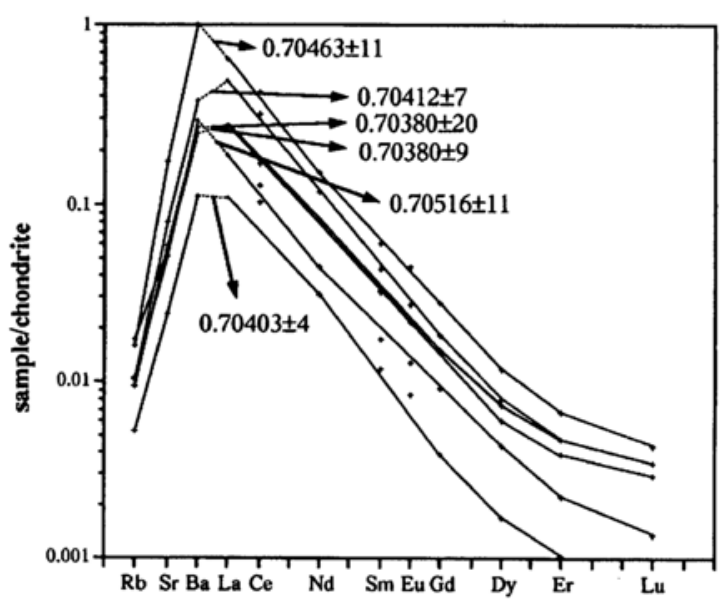

Fig. 1. REE + Ba, Sr, Rb patterns and Sr isotope ratios for Zairean fibrous diamonds.

Table 1. Rb, Sr and REE abundances (unit; $\mu \mathrm{g} / \mathrm{g}$ of diamond) and $\mathrm{Sr}$ isotope ratios for whole cubic diamonds

\begin{tabular}{|c|c|c|c|c|c|c|}
\hline & CS-9* & CS-10* & CS-11* & CS-12 & CS-13* & CL-8* \\
\hline $\mathrm{Rb}$ & 14.9 & 28.9 & 26.5 & 48.5 & 44.5 & 29.4 \\
\hline $\mathrm{Sr}$ & 273 & 893 & 655 & 620 & 1920 & 569 \\
\hline $\mathrm{Ba}$ & 466 & 1580 & 1130 & 1060 & 4200 & 1240 \\
\hline $\mathrm{La}$ & 41.2 & 183 & 103 & 106 & 240 & 71.8 \\
\hline $\mathrm{Ce}$ & 99.6 & 316 & 166 & 176 & 417 & 126 \\
\hline $\mathrm{Nd}$ & 22.2 & 84.2 & 58.8 & 59.4 & 108 & 32.3 \\
\hline $\mathrm{Sm}$ & 2.75 & 9.95 & 7.61 & 7.47 & 14 & 3.97 \\
\hline $\mathrm{Eu}$ & 0.73 & 2.36 & & 1.86 & 3.9 & 1.12 \\
\hline Gd & 1.22 & 5.76 & 4.75 & 4.66 & 8.76 & 2.84 \\
\hline Dy & 0.658 & 3.09 & 2.37 & 2.88 & 4.61 & 1.69 \\
\hline $\mathrm{Er}$ & 0.264 & 1.2 & 0.981 & 1.22 & 1.74 & 0.57 \\
\hline Lu & & & 0.113 & 0.135 & 0.169 & 0.053 \\
\hline${ }^{87} \mathrm{Sr} /{ }^{86} \mathrm{Sr}^{* *}$ & $0.70403 \pm 4$ & $0.70412 \pm 7$ & $0.70380 \pm 20$ & $0.70380 \pm 9$ & $0.70463 \pm 11$ & $0.70516 \pm 11$ \\
\hline
\end{tabular}

*Data from Akagi and Masuda (1988).

**Deviation represents $l \sigma$. 
tributed in a much wider range (Fig. 2). The wider compositional variation of Botswana diamonds than Zaire diamonds has been pointed out by Schrauder and Navon (1994). The reason for the much wider variation of Botswana diamonds shall be discussed later. I found that the variation correlates further with $\mathrm{Sr}$ isotope ratios. The correlations between $\mathrm{Sr}$ isotopic ratios and elemental compositions are shown in Fig. 3. There are some lines of evidence, which relate the formation of the fibrous diamond with the kimberlitic magmatism (Akagi and Masuda, 1988; Boyd et al., 1994). The initial $\mathrm{Sr}$ isotopic ratios calculated at the assumed eruption age of the Mbuji Mayi kimberlite (Demaiffe and Fieremans, 1981) are plotted in Fig. 3. The $\mathrm{Sr}$ isotope ratio increases with increasing $\mathrm{La} / \mathrm{Nd}$ ratio and decreasing $\mathrm{La} / \mathrm{Ba}$ ratio and the trend holds good even at the assumed eruption age.

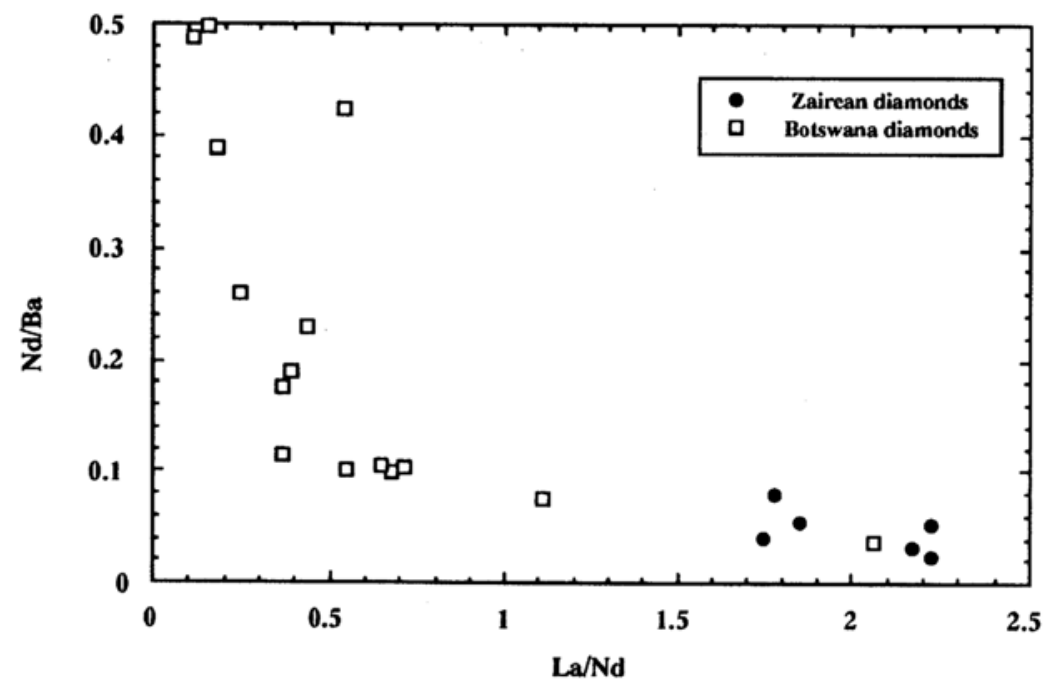

Fig. 2. Relationship between La/Nd and Nd/Ba in Zairean fibrous diamonds and Botswana fibrous diamonds reported by Schrauder et al. (1996).
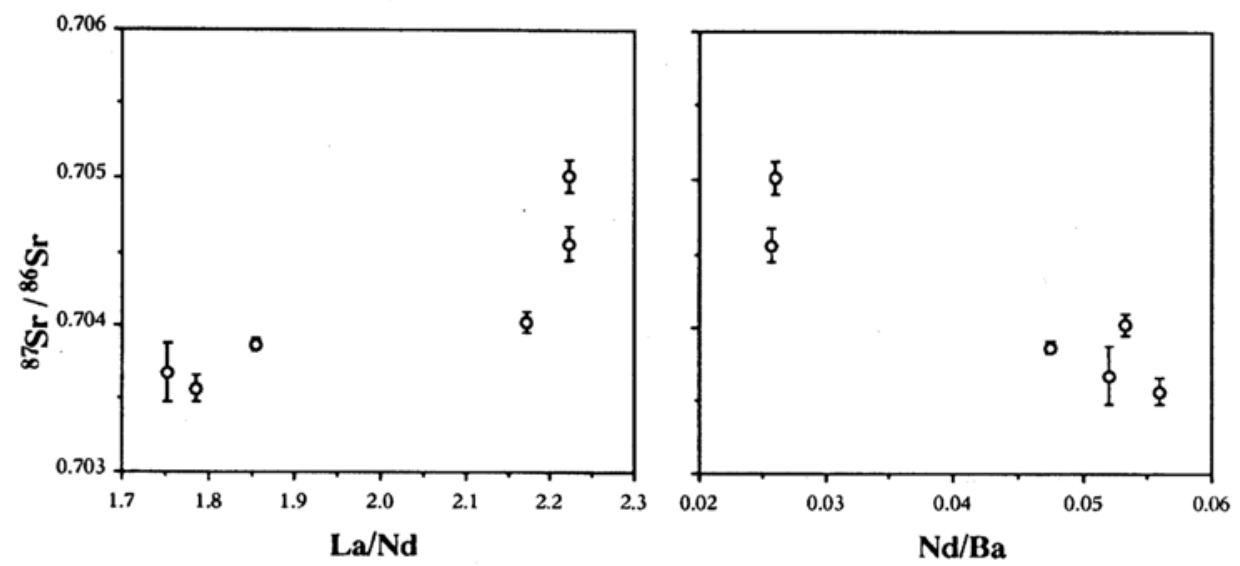

Fig. 3. Relation between initial ${ }^{87} \mathrm{Sr} /{ }^{86} \mathrm{Sr}$ ratios and (a) La/Nd and (b) Ba/La ratios for Zairean fibrous diamonds. The initial ${ }^{87} \mathrm{Sr} /{ }^{86} \mathrm{Sr}$ ratios are calculated assuming the age of diamond is the same as a local kimberlite pipe (Akagi and Masuda, 1988). 
Table 2. Results of leaching experiments on crushed diamonds (unit of abundance; $\mu \mathrm{g} / \mathrm{g}$ of diamond)

\begin{tabular}{lccccc}
\hline & \multicolumn{3}{c}{ CS-1 } & & \multicolumn{2}{c}{ CS-2 } \\
\cline { 2 - 3 } \cline { 5 - 6 } & water & $\mathrm{HCl}$ & & water & $\mathrm{HCl}$ \\
\hline $\mathrm{Sr}$ & 122 & 99.7 & & 47.8 & 130 \\
$\mathrm{Ba}$ & 1320 & 593 & & 395 & 531 \\
$\mathrm{La}$ & 21.2 & 141 & & 19 & 241 \\
$\mathrm{Nd}$ & 9.5 & 122 & & 9.34 & 132 \\
$\mathrm{Ga}$ & 0.67 & 11 & & 0.806 & 11.2 \\
${ }^{87} \mathrm{Sr} /{ }^{86} \mathrm{Sr} *$ & $0.70454 \pm 19$ & $0.70399 \pm 34$ & & $0.70540 \pm 25$ & $0.70410 \pm 30$ \\
\hline
\end{tabular}

*Deviation represents $l \sigma$.

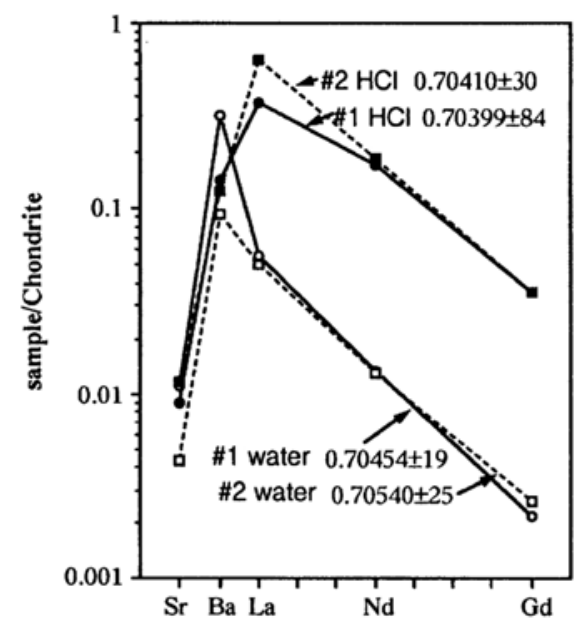

Fig. 4. REE $+\mathrm{Ba}, \mathrm{Sr}$ patterns and $\mathrm{Sr}$ isotope ratios for leachates from Zairean fibrous diamonds. Leaching experiments were carried out twice using water and then twice with $3 \mathrm{~N} \mathrm{HCl}$.

\section{Leaching experiments}

The results of the leaching experiments are shown in Table 2. All of them are new data. The first leaching performed with water extracted a portion of trace impurities in the diamonds and it was followed by acid leaching. It was found that the co-variation seen in the results of the combustion experiments on several pieces of the whole diamond is reproduced in the leaching experiments on a single diamond. The patterns for the water leachates exhibit straight or upward-bend in LREE region (higher $\mathrm{La} / \mathrm{Nd}$ ) and lower $\mathrm{Nd} / \mathrm{Ba}$ ratio and the $\mathrm{HCl}$ leachates a slight downward-bend (lower
$\mathrm{La} / \mathrm{Nd}$ ) with lower $\mathrm{Nd} / \mathrm{Ba}$ ratios (Fig. 4). I measured $\mathrm{Sr}$ isotope ratios for the two leachates. The first water leachate with higher $\mathrm{La} / \mathrm{Nd}$ and lower $\mathrm{Nd} / \mathrm{Ba}$ ratios gave relatively higher $\mathrm{Sr}$ isotope ratio and the second $\mathrm{HCl}$ leachate with lower $\mathrm{La} /$ $\mathrm{Nd}$ and higher $\mathrm{Nd} / \mathrm{Ba}$ gave lower $\mathrm{Sr}$ isotope ratio. The relationship between the abundance ratio and $\mathrm{Sr}$ isotope ratio in the leaching experiment is the same as seen in the combustion experiments.

Taking the results of the combustion and leaching experiments into consideration, it might be convenient to refer the water soluble inclusions with high $\mathrm{Sr}$ isotopic ratios, higher $\mathrm{La} / \mathrm{Nd}$ and lower $\mathrm{Nd} / \mathrm{Ba}$ ratios to type $\mathrm{A}$, and acid soluble ones with low $\mathrm{Sr}$ isotopic ratios, lower $\mathrm{La} / \mathrm{Nd}$ and higher $\mathrm{Nd} / \mathrm{Ba}$ ratios to type $\mathrm{B}$.

\section{Discussion}

\section{Uncertainty and contamination}

The crushing and leaching method is a "crude" technique and not strictly defined to specific substances leaving some uncertainty to the results. In addition, elements may exchange or diffuse among substances in inclusions during geological time, which may shroud the results. The finding of the same correspondance between the pattern type and $\mathrm{Sr}$ isotopic ratio in both the combustion and leaching methods, however, indicates that the two types have been preserved well to be detectable.

The different isotopic signatures between the two leachates may be interpreted to indicate that the water and acid attacked different parts of the 
minerals, each part of which originally would have "isochronous" (in other words, $\mathrm{Rb}$ related) $\mathrm{Sr}$ isotope ratios. The plotting of $\mathrm{Sr}$ isotope data against $\mathrm{Rb} / \mathrm{Sr}$ ratio, however, fails to form a linear line ruling out the possibility, the same as the results of the combustion experiments (Akagi and Masuda, 1988).

Some diamond specimens have cracks. There is a concern that the diamonds have been contaminated during the ascent or after kimberlite eruption, and it is possible that the observed heterogeneity is a merely apparent one caused by contamination. If this is the case, either one of the two types could correspond to contamination. Both the types are featured with very steep slopes in their REE patterns. The steepness is unusual in crust, but is similar to that of kimberlite or carbonatite. If it had been contaminated with crustal components of less steepness, the slope in HREE region would be less steeper. It is considered that the components of types $\mathrm{A}$ and $\mathrm{B}$ are those in the upper mantle, not contaminated with crustal matter.

\section{Origin of the inclusions}

Solubilities of inorganic substances have been well-summarized by chemists. Chloride and nitrate salts are soluble with water and carbonates and oxides are usually dissolved by acids. It is reported that one of the major impurities of the micro-inclusions in fibrous diamonds is chlorine (Ozima et al., 1989; Turner et al., 1990) and the leaching with water possibly liberated the chloride salts, as the salts of $\mathrm{REE}, \mathrm{Rb}, \mathrm{Sr}$ and $\mathrm{Ba}$ are readily soluble with water. It is considered that the salts may not have existed in the diamonds, but may have been produced from water-rich fluid after crushing. $\mathrm{HCl}$ leaching is considered to attack carbonates, as carbonates are the major impurity in the diamonds (Navon et al., 1988). The two substances need to have been immisible with each other even in a tiny scale like a piece of diamond to preserve difference in $\mathrm{Sr}$ isotope ratio between the two types.

The lower $\mathrm{Sr}$ isotopic ratio of acid leachable fraction favours higher $\mathrm{Sr} / \mathrm{Rb}$ ratio of the source for the type B. If the source is carbonates, the higher "time-integrated" $\mathrm{Sr} / \mathrm{Rb}$ ratio is quite natural from geochemical point of view. Much steeper pattern was anticipated for the fluid in equilibrium with garnets (Shimizu and Richardson, 1987) and the observed pattern of the types A can be created by mixing component of type B and such fluid of higher steepness. From the isotopic and REE signature the two types could be most probably carbonate-rich carbonatitic melt and highly fluidal water-rich component.

Navon et al. (1988) reported that the micro inclusions in Zaire cubic diamonds are enriched in $\mathrm{Na}$ and $\mathrm{K}$ compared with kimberlite. The present results might exhibit a resolution of their mixed-up data, probably carbonatitic melt (type B) plus fluid (type A). The difference in $\mathrm{Sr}$ isotopic composition indicates the fluid has not originated from the crystallization of parental kimberlitic magma.

Schrauder and Navon (1994) carried out IR and EPMA analyses on Botswana cubic diamonds and reported a positive correlation between $\mathrm{H}_{2} \mathrm{O}$ / $\left(\mathrm{H}_{2} \mathrm{O}+\mathrm{CO}_{2}\right)$ and $\mathrm{SiO}_{2}$ and a negative one between $\mathrm{SiO}_{2}$ and incompatible elements. From the two correlations they concluded correlation between the carbonates and incompatibe elements. Their classification seems valid as long as carbonates are dominant inclusions. Actually Fig. 4 suggests that carbonates are a dominant source for REE, but a little less dominant one for Sr. They classified REE, $\mathrm{Sr}$ and $\mathrm{Ba}$ into the same incompatible elements, but the plot of $\mathrm{La} / \mathrm{Nd}$ and $\mathrm{Nd} /$ $\mathrm{Ba}$ using their data (Fig. 2) clearly shows widely varying chemistry even among the incompatible elements. Botswana diamonds are considered to generally be more enriched in carbonate inclusions than Zaire diamonds, which explains lower $\mathrm{La} /$ $\mathrm{Nd}$ and higher $\mathrm{Na} / \mathrm{Ba}$ ratios except one sample. The present data show that the $\mathrm{La} / \mathrm{Nd}$ and $\mathrm{Nd} / \mathrm{Ba}$ variations are correlated with $\mathrm{Sr}$ isototopic composition. It is likely that the variation reflects the difference in composition and isotopic signature of incompatible elements between $\mathrm{H}_{2} \mathrm{O}-\mathrm{SiO}_{2}$ and carbonate phases (with most incompatible elements), as silicate fluid is immiscible with carbonate melt under a certain condition (Falloon and 
Green, 1990). Schrauder et al. (1996) introduced four models to explain the negative correlation of $\mathrm{SiO}_{2}$ and incompatible elements: partial melting of carbonate-bearing peridotites, partial melting of eclogites, fractional crystallization, and mixing of fluids. Difference in $\mathrm{Sr}$ isotope ratio between the two types of inclusions observed in this study rules out the fractional crystallization model. The partial melting models cannot be excluded, as in the models there is a little chance to create the observed difference in $\mathrm{Sr}$ isotopic ratio. The present results, however, favour the mixing of fluids most, carbonate rich fluid (or melt) and silicate fluid equilibrated with high $\mathrm{Sr}$ isotopic component such as crust. Even if the contribution of the silicate fluid is minor with respect to REE pattern, the $\mathrm{Sr}$ isotopes could be affected because of relatively higher $\mathrm{Sr} / \mathrm{REE}$ ratio in silicate fluid than in carbonates as can be inferred from Fig. 4. This consideration anticipates that the variation in $\mathrm{Sr}$ isotope composition for Botswana diamonds would be small except one sample since they might have been more enriched in carbonates than Zaire diamonds.

\section{Isotopic heterogeneity of the upper mantle}

Both the types of A and B are likely to have been derived from the upper mantle, and carbonatitic melt (or fluid) and fluid have had different $\mathrm{Sr}$ isotopic compositions and thus in origin, evoking the heterogeneity of the upper mantle. Among the several interpretations of the isotopic feature of kimberlite are the isotopic heterogeneity of the upper mantle, the open system behavior and weathering after eruption. The previous discussion suggests that the diamonds might have preserved the heterogeneous isotopic feature of the upper mantle in their robust structure, which would thus support the isotopic heterogeneity of the upper mantle as an interpretation of the isotopic feature of kimberlite.

\section{Constraint on the formation of the diamonds}

The fibrous diamonds are considered to have formed rapidly, and also very small aggregation state of nitrogen observed by IR study also sug- gests that the diamonds have been brought to the earth surface in relatively short time after their production (Boyd et al., 1994). If we admit that the diamonds have been brought to the surface shortly after the formation, it is rather natural to consider that the mixing of the carbonate-rich melt or fluid and water-rich fluid has triggered the diamond formation and kimberlite magmatism as well. The inclusions trapped in the diamonds could be the substances occurred at the very first stage of the magmatism.

Acknowledgments-I thank Dr. Marcus Schrauder, Vienna University, for his discussion and enlightening me as to diamond mineralogy. I also express my thanks to Dr. Peter van Calsteren, the Open University, and Professor Akimasa Masuda, Professor Emeritus Tokyo University, for their reading the manuscript and productive discussion.

\section{REFERENCES}

Akagi, T. and Masuda, A. (1988) Isotopic and elemental evidence for a relationship between kimberlite and Zaire cubic diamonds. Nature 336, 665-667.

Boyd, S. R., Mattey, D. P., Pillinger, C. T., Milledge, H. J., Mendelssohn, M. and Seal, M. (1987) Multiple growth events during diamond genesis: an integrated study of carbon and nitrogen isotopes and nitrogen aggregation state in coated stones. Earth Planet Sci. Lett. 86, 341-353.

Boyd, S. R., Pineau, F. and Javoy, M. (1994) Modelling the growth of natural diamonds. Chem. Geol. 116, $29-42$.

Demaiffe, D. and Fieremans, M. (1981) Strontiumisotopic geochemistry of the Mbuji Mayi and Kundelungu Kimberlites (Zaire, Central Africa). Chem. Geol. 31, 311-323.

Falloon, T. J. and Green, D. H. (1990) Solidus of carbonated fertile peridotite under fluid-saturated conditions. Geology 18, 195-199.

Faure, G. (1986) Isotope geology of neodymium and strontinum in igneous rocks. In Isotope Geology, 217-248, Wiley \& Sons, New York.

Melton, C. E. and Giardini, A. A. (1974) The composition and significance of gas released from natural diamonds from Africa and Brazil. Am. Mineral. 59, 775-782.

Navon, O. (1991) High internal pressures in diamond fluid inclusions determined by infrared absorption. Nature 353, 746-748. 
Navon, O., Hutcheon, I. D., Rossman, G. R. and Wasserburg, G. J. (1988) Mantlederived fluids in diamond micro-inclusions. Nature 335, 784-789.

Ozima, M., Zashu, S., Takigami, Y. and Turner, G. (1989) Origin of the anomalous ${ }^{40} \mathrm{Ar}-{ }^{39} \mathrm{Ar}$ age of Zaire cubic diamonds: excess ${ }^{40} \mathrm{Ar}$ in pristine mantle fluids. Nature 337, 326-329.

Schrauder, M. and Navon, O. (1994) Hydrous and carbonatitic mantle fluids in fibrous diamonds from Jwaneng, Botswana. Geochim. Cosmochim. Acta 58, 761-771.
Schrauder, M., Koeberl, C. and Navon, O. (1996) Trace element analyses of fluidbearing diamonds from Jwaneng, Botswana. Geochim. Cosmochim. Acta 60, 4711-4724.

Shimizu, N. and Richardson, S. H. (1987) Trace element abundance patterns of garnet inclusions in peridotite-suite diamonds. Geochim. Cosmochim. Acta 51, 755-758.

Turner, G., Burgess, R. and Bannon, M. (1990) Volatile-rich mantle fluids inferred from inclusions in diamond and mantle xenoliths. Nature 344, 653-655. 